\title{
Direct Lightning Current Measurements in southeastern Brazil II: Correlations
}

\author{
Moacir Lacerda* \\ Osmar Pinto Jr.* \\ Iara José H. Diniz** \\ André M. Carvalho** \\ R.C.A. Pinto*
}

Instituto Nacional de Pesquisas Espaciais, São José dos Campos, São Paulo, Brazil*

Companhia Energetica de Minas Gerais, Belo Horizonte, Minas Gerais, Brazil**

\begin{abstract}
This paper shows data associated with 50 subsequent return stroke of 22 natural negative descendent lightining discharges in Brazil captured by a $60 \mathrm{~m}$ metalic tower, between 1985 and 1994. It is investigated the possible correlations among the time to peak value of derivative current, time to peak current, the peak value of the electric current, and the peak value of the derivative current.We discuss some physical consequences relating to them. We suggest that there may be a non-linear correlation between the time to peak occurence and the magnitude of these parameters.
\end{abstract}

\section{INTRODUCTION.}

This paper is a sequence of paper $1^{(1)}$, where some general aspects of data acquired by CEMIG LIGHTNING RESEARCH STATION (CLRS) $)^{(2)}\left(43^{\circ}\right.$ $\left.58^{\prime} 26^{\prime \prime} \mathrm{W}, 20^{\circ} 00^{\prime} 39^{\prime \prime} \mathrm{S}\right)$ were presented. We present here some correlations among several parameters of subsequent strokes: $t_{d m}$ (time to peak value of derivative current), $t_{\text {peak }}$ (time to peak current), $I_{\text {peak }}$ (peak value of the current), and (di/dt) $\max$ (peak value of derivative current $\mathrm{di} / \mathrm{dt}$ ).

\section{DATA ANALYSIS}

Figure 1 presents the correlation between $t_{d m}$ and $t_{\text {peak }}$. It shows that the instant when the peak current occurs is correlated with the instant of peak derivative current, with a correlation coeficient of $94 \%$. This fact allows to conclude that the instant of peak radiation as calculated according a mathematical model of a radiating antena ${ }^{(3)}$ is correlated with the instant of current peak. Otherwise, figure 2 shows that there is no correlation between the magnitudes of $\mathrm{I}_{\text {peak }}$ and $(\mathrm{di} / \mathrm{dt})_{\max }$. The mean values for $\mathrm{t}_{\text {peak }}$ and $\mathrm{t}_{\mathrm{dm}}$ are $1.75 \mu \mathrm{s}$ and $1.09 \mu \mathrm{s}$, respectively. The mean value for $\mathrm{I}_{\text {peak }}$ and $(\mathrm{di} / \mathrm{dt})_{\max }$ are $18.07 \mathrm{kA}$ and $32.82 \mathrm{kA} / \mu \mathrm{s}$, respectively.

Figures 3 shows that mean values of (di/dt)max increase for $t_{d m}$ lower than 1.0 microsecond and figure 4 shows that mean values of $I_{\text {peak }}$ increase for $t_{\text {peak }}$ lower than 1.5 microsecond.In both cases the parameters decrease after a maximum.The meaning of this fact is that there may be some factors which tends to increase $I_{\text {peak }}$ or $(\mathrm{di} / \mathrm{dt})_{\max }$ and others which reduces their intensities. Depending on the values of $t_{\mathrm{dm}}$ and $t_{\text {peak }}$, some factors predominate over the others.

\section{CONCLUSION}

Data of 50 subsequent strokes of natural lightning flashes which striken a $60 \mathrm{~m}$ metalic tower in Brazil are used to obtain some correlations between electric parameters. The main conclusions are:

1)The instant of time of maximum derivative current is correlated with the instant of peak current. Otherwise, the values of maximum derivative current and peak current are not correlated. This fact may indicate that the current waveform presents approximatly the same shape, while increasing,. for all discharges. .

2) Apparently there may be a non-linear correlation between the instant of occurrence of peak current and its magnitude and between the time to peak derivative current and the magnitude of this parameter. No explanations for these facts exist.

\section{ACKNOWLEDGMENTS}

We acknowledge all the technical personnel of CEMIG for laborious work in maintaiting the CACHIMBO'S STATION and specially to Eng. Jacinto Soares Filho and Eng. Carlos Alexandre Meireles do Nascimento for pre-treatment of data, information and "help on line" given.

\section{REFERENCES}

Lacerda, M., Pinto Jr., O., Pinto, I. C. A., Diniz, J. H., Carvalho, A. M., Direct Lightning Current Measurements in Southeastern Brazil I. Current Waveform; This proceeding.

Soares Filho, J. J., Carvalho, A. M., Diniz, J. H., Parâmetros de Descargas Atmosféricas; Resultados de 9 anos dePesquisa na Estação do Cachimbo Período 1985-1994. Relatório no 02.110 ST/DN1-001 CEMIG, Dez 1995.

Uman, M., The Lightning Discharge, Academic Press, Inc.London, 1987. 

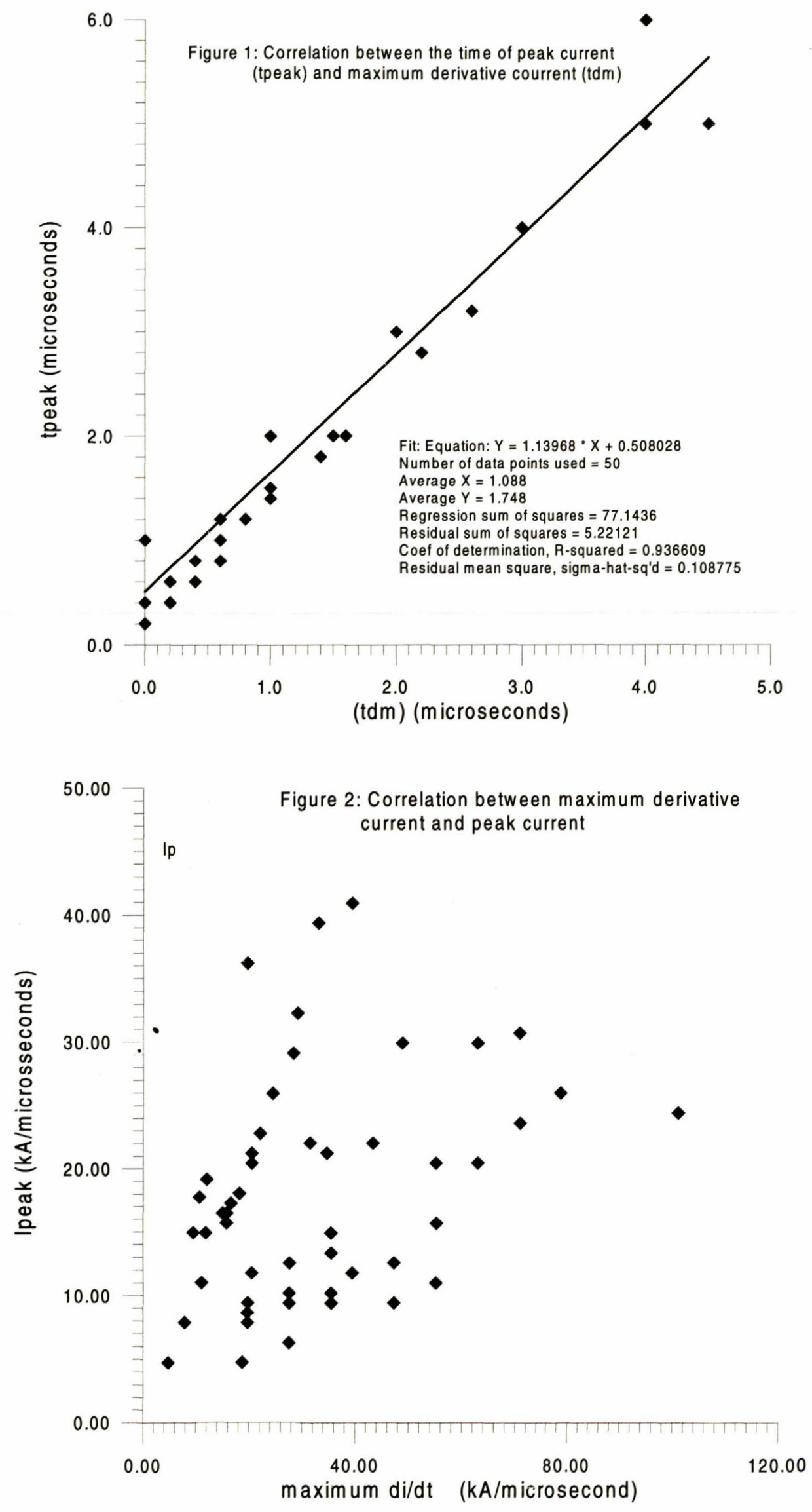

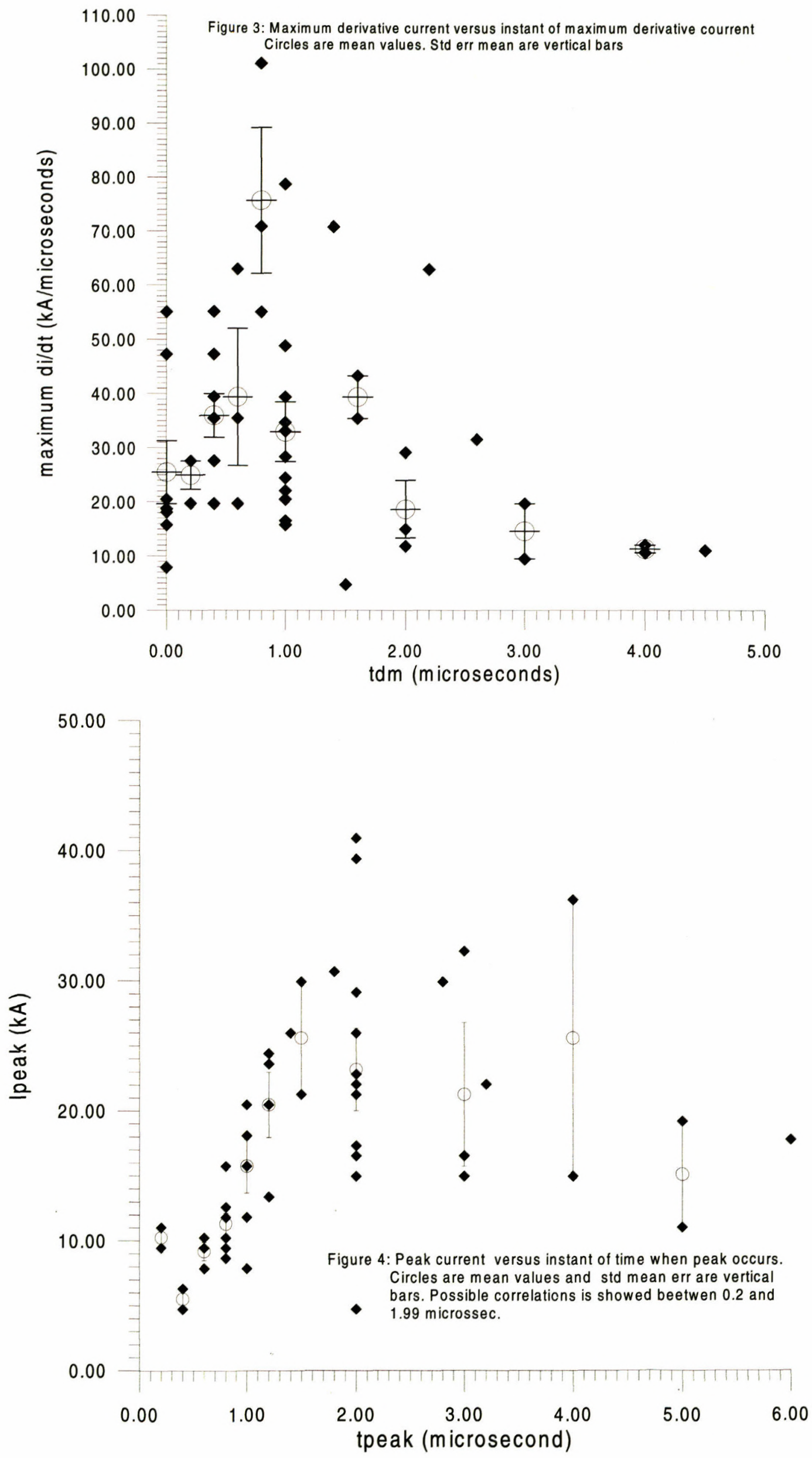